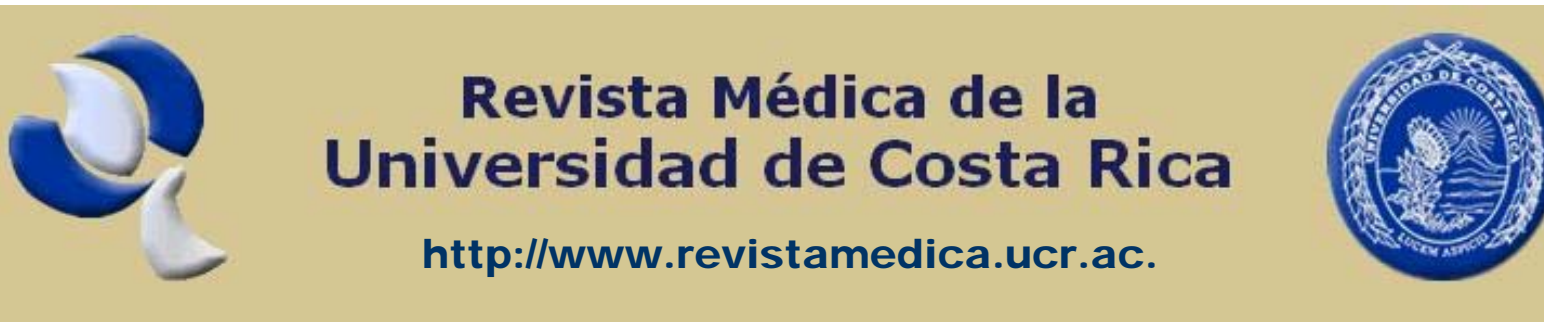

\title{
Determinación de la efectividad de cinco protocolos de extracción de ADN a partir de material parafinado para estudios moleculares.
}

\author{
Jiménez Arce Gerardo ${ }^{1}$, Villalobos Quesada María José ${ }^{1,2}$, Jiménez Montero \\ Ernesto $^{3}$ y Palma Platero Walter ${ }^{4}$
}

1. Centro de Investigación en Hematología y Trastornos Afines (CIHATA-UCR), 2. Instituto Tecnológico de Costa Rica (ITCR), 3. Servicio de Anatomía Patológica, Hospital San Juan de Dios (HSJ D) y Servicio de Anatomía Patológica, Hospital Calderón Guardia (HCG).

Resumen: El estudio evaluó cuatro distintos protocolos de uso común en laboratorio y uno comercial, para la extracción de ADN a partir de material fijado en formalina y parafinado, correspondiente a cervix uterinos producto de conizaciones y LEEPs (loop electrocautery excision procedure), provenientes de los Servicios de Patología de nueve Hospitales de la Caja Costarricense de Seguro Social (CCSS). Se encontró que el protocolo más efectivo para obtener ADN viable para la PCR, es el basado en extracción fenólica y que la calidad del ADN se ve profundamente afectada por el proceso de preservación al que se ven sometidos los tejidos en los diferentes servicios. El promedio general de amplificación estuvo por debajo del $50 \%$. El rango de amplificación por servicio va desde el $0 \%$, hasta el $70 \%$. Las razones por las que la PCR a partir de ADN aislado de parafinadas resulta inconsistente, se pueden resumir, a grosso modo, en: baja cantidad o ausencia de ADN blanco detectable, presencia de inhibidores, degradación del ADN total blanco y fragmentación de los ácidos nucleicos debido a la fijación en formalina.

Palabras clave: Patología molecular, PCR, ADN, formalina, parafinado, CCSS.

Recibido: junio 2007. Aceptado: Agosto. Publicado: Septiembre 2007.

Revista electrónica publicada por la Escuela de Medicina de la Universidad de Costa Rica, 
Abstract: This study evaluated four different laboratory protocols and a commercial one, for DNA extraction from formalin-fixed and paraffined material corresponding to uterine cervix tissue and LEEPs, from the Pathology Departments of nine hospitals belonging to the CCSS (Costa Rican Social Security System). The results showed that the most effective protocol was the one based on phenolic extraction. It was also observed that the DNA quality is severely affected by the preservation process. The amplification average was below $50 \%$. The rank of amplification depending on the hospital and the protocol used goes from 0 to $70 \%$. The reasons why the PCR from paraffined isolated DNA samples results inconsistent could be due to low quantity, absence of detectable target DNA, presence of inhibitors, target DNA degradation and nucleic acid fragmentation due to fixation in formalin.

Keywords: molecular pathology, PCR, DNA, formalin-fixed, paraffined, CCSS.

\section{Introducción}

Los especímenes fijados en formalina y parafinados, además de conservarse para análisis histológicos, representan una importante fuente de material para la investigación retrospectiva a nivel molecular, pues obvian la necesidad de tejido fresco para el diagnóstico, son de fácil manejo y práctico almacenamiento, entre otras ventajas [1,2].

Múltiples factores parecen incidir en la calidad molecular (calidad y cantidad de ADN extraíble sometible a análisis moleculares) de las muestras parafinadas, como el fijador (naturaleza, concentración, temperatura, $\mathrm{pH}$ ), tiempo de fijación, tamaño del tejido fijado y edad del bloque [3-9].

La calidad y cantidad del material genético extraído destacan como los factores limitantes para realizar pruebas moleculares a partir de este material. Ante esto, la eficiencia de los procedimientos de extracción se ha convertido en un punto crítico para el éxito de la aplicación de la PCR $[6,7,9]$.

A pesar de que la arquitectura de los tejidos se preserva, la extracción de los ácidos nucleicos generalmente se reduce a recuperar ADN degradado, lo que limita los análisis que requieran ADN de alta integridad, como la Southern Blot; sin embargo, es un sustrato viable para la PCR $[1,2,10,11]$. En Costa Rica, pruebas preliminares sugieren limitantes de calidad y cantidad de ADN óptimo para PCR en este tipo de muestras, lo que podría afectar el tipo de análisis o restringir la antigüedad de los bloques parafinados utilizados en este tipo de estudio [3].

En este estudio se evaluaron cinco protocolos de extracción de ADN, a partir de muestras parafinadas del Laboratorio de Anatomía Patológica, del Hospital San Juan de Dios, de la Caja Costarricense de Seguro Social (CCSS). Posteriormente se determinó el estado del ADN y su viabilidad para la PCR diagnóstica (amplificación de fragmentos de una longitud suficiente para llevar a cabo pruebas moleculares diagnósticas). Con el protocolo elegido como el más eficiente, se evaluó el material parafinado de nueve Servicios de Patología de la CCSS.

Revista electrónica publicada por la Escuela de Medicina de la Universidad de Costa Rica, 


\section{Materiales y Métodos}

I. Evaluación de protocolos de extracción: A partir de cortes de tejidos parafinados, se realizaron extracciones por duplicado de diez bloques parafinados de muestras de cervix uterinos producto de conizaciones y LEEPs fijados en formalina buferizada al $10 \%$ del Hospital San Juan de Dios, con periodos de almacenamiento menores a ocho meses. Se evaluaron cinco protocolos de extracción de ADN. Método 1: A tres cortes de $10 \mu \mathrm{m}$ se agregaron $100 \mu \mathrm{l}$ de Tris $50 \mathrm{mM} \mathrm{pH} 8.0$ y se fundieron a $100^{\circ} \mathrm{C} 10$ minutos y se dejaron enfriar. Se agregó $5 \%$ de Proteinasa $\mathrm{K}(20 \mathrm{mg} / \mathrm{ml})$ y se incubó toda la noche a $55^{\circ} \mathrm{C}$ en agitación continua. Se añadió $5 \%$ de Chelex al $5 \%$, se incubó 30 minutos más, y luego a $100^{\circ} \mathrm{C}$ durante 5 minutos y se centrifugó a 12 $000 \mathrm{~g}$ por 15 minutos. Se trasvasó el sobrenadante a un microtubo limpio y se almacenó a $-20^{\circ} \mathrm{C}$ [12]. Método 2: Dos cortes de $10 \mu \mathrm{m}$ se desparafinaron (dos veces) en $1 \mathrm{ml}$ de xilol por 30 minutos; se centrifugaron a $12000 \mathrm{~g}, 10$ minutos, se descartó el sobrenadante y se agregó $1 \mathrm{ml}$ de etanol al $100 \%$, se agitó manualmente, se esperó 30 minutos, se centrifugó y descartó el sobrenadante. Igualmente se agregó $1 \mathrm{ml}$ de etanol al $70 \%$, y $1 \mathrm{ml}$ de PBS (dos veces). Se agregó $500 \mu \mathrm{l}$ de amortiguador de lisis $(50 \mu$ l Proteinasa K 20mg/ml; $10 \mu \mathrm{l}$ Tris$\mathrm{HCl} 1 \mathrm{M} ; 2 \mu \mathrm{l}$ EDTA $0,5 \mathrm{M} ; 100 \mu \mathrm{l}$ SDS $10 \%$ y $838 \mu l$ agua destilada) y se incubó toda la noche a $52^{\circ} \mathrm{C}$ en agitación continua. Se agregó 500 $\mu \mathrm{l}$ de fenol:cloroformo:isomilalcohol (25:24:1), se agitó y se centrifugó por 5 minutos. El sobrenadante se removió a otro microtubo, se agregó 0,1 volumen de acetato de sodio $3 \mathrm{M}$ y se agitó manualmente. Se adicionó un volumen de isopropanol y se almacenó toda la noche a $-20^{\circ} \mathrm{C}$. Se centrifugó, el sobrenadante se descartó y el precipitado se lavó una vez con $1 \mathrm{ml}$ de etanol $70 \%$, se centrifugó y descartó el sobrenadante. EI ADN seco se disolvió en $50 \mu \mathrm{l}$ de agua bidestilada estéril y se almacenó a $-20^{\circ} \mathrm{C}$ [5]. Método 3: Cuatro cortes de $10 \mu \mathrm{m}$ se desparafinaron en $400 \mu l$ de xilol, se mezcló con vórtex, se incubó 30 minutos, se le dio vórtex dos veces, se centrifugó por 5 minutos a $13000 \mathrm{~g}$ y se descartó el xilol. Se agregaron $100 \mu l$ de etanol:xilol (80:20) y se incubó 30 minutos a $37^{\circ} \mathrm{C}$, se centrifugó y se descartó el sobrenadante. Se añadió $400 \mu \mathrm{l}$ de etanol $100 \%$, se incubó media hora a $37^{\circ} \mathrm{C}$, se centrifugó y se descartó el etanol. Una vez desparafinado el tejido se utilizó el "Extract-N-AmpTM Tissue PCR Kit" (Sigma- Aldrich) [13]. Método 4: Cinco cortes de $4 \mu \mathrm{m}$ se desparafinaron dos veces: se agregó $1 \mathrm{ml}$ de xilol, se agitaron manualmente, se centrifugaron a $12000 \mathrm{rpm}$ por 3 minutos y se decantó. Se repitió el proceso con $1 \mathrm{ml}$ etanol $100 \%$ y $1 \mathrm{ml}$ etanol $70 \%$, se dejó secar. Se lavó con un amortiguador (Tris- $\mathrm{HCl} 100 \mathrm{mM} \mathrm{pH}$ $8.3, \mathrm{KCl} 500 \mathrm{mM}, \mathrm{MgCl} 215 \mathrm{mM})$, se centrifugó y se decantó. Se volvió a agregar amortiguador hasta cubrir el tejido. Se sometió a radiación en el microondas 6 minutos a potencia media, deteniéndolo cada 15 segundos, se centrifugó y se pasó el sobrenadante a un microtubo limpio y se almacenó a $20^{\circ} \mathrm{C}$ [14]. Método 5: A 2 cortes de $5 \mu \mathrm{m}$ se les agregó $100 \mu l$ de xilol y $100 \mu l$ de etanol $100 \%$, se mezcló suavemente y centrifugó 10 minutos a 12 000 rpm. Se decantó y secó el tejido a $55^{\circ} \mathrm{C}$. Se resuspendió el botón en $250 \mu$ l de Tris

Revista electrónica publicada por la Escuela de Medicina de la Universidad de Costa Rica, 


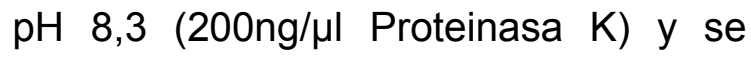
incubó toda la noche a $37^{\circ} \mathrm{C}$ en agitación continua. Se colocaron los tubos 8 minutos a $100^{\circ} \mathrm{C}$, se colocó el ADN 5 minutos en hielo y se almacenó a $-20^{\circ} \mathrm{C}[9]$.

El producto obtenido con cada uno de los métodos se evaluó según: integridad (electroforesis en gel de agarosa al 1\%, contra un marcador de peso molecular, revelado con bromuro de etidio, que se analizó mediante el software Kodak Digital Science 1D), pureza y concentración (cuantificación del ADN por espectrofotometría de luz ultravioleta), y calidad del ADN (viabilidad para la PCR utilizando los iniciadores $\quad \mathrm{PCO} 4$ CAACTTCATCCACGTTCACC-3') y $\mathrm{GH} 20$

GAAGAGCCAAGGACAGGTAC-3'), para el gen de la $\beta$-globina (producto de 267pb). El protocolo considerado como el más eficiente, se usó para procesar las muestras de los otros Servicios de Anatomía Patológica.

Para la amplificación se utilizaron las siguientes condiciones: amortiguador de PCR 1X, dNTP's 0,2mM, $\mathrm{MgCl}_{2} 2 \mathrm{mM}$, PC04 0,5pmol, GH20 0,5pmol, Taqpolimerasa $1 \mathrm{U}$ y $A D N 2 \mu$, volumen final $25 \mu \mathrm{l}$ (en el caso de las muestras extraídas con el Extract-N-AmpTM Tissue PCR Kit, se hizo según indicaciones y reactivos del fabricante). Con el siguiente perfil de PCR: pretratamiento $94^{\circ} \mathrm{C} 5$ minutos, seguido de 30 ciclos de $94^{\circ} \mathrm{C}$ por 30 segundos, $55^{\circ} \mathrm{C} 30$ segundos y $72^{\circ} \mathrm{C} 30$ segundos, con un paso final de extensión a $72^{\circ} \mathrm{C}$ 10 minutos.

La valoración de los productos de PCR se realizó por electroforesis en un gel de agarosa al $3 \%$. El control positivo de amplificación se preparó a partir de ADN de sangre periférica de hígado fresco extraído con el Método reportado por Miller y colaboradores [10].

II. Valoración del estado de las muestras de los Servicios de Patología de la CCSS: Se recolectaron 10 bloques de parafina de cada servicio de anatomía patológica de los siguientes hospitales de la CCSS: México (HM), Calderón Guardia (HCG), de la Mujer Carit (HMC), Max Peralta (HMP), Toni Facio (HTF), San Carlos (HSC) y Escalante Pradilla (HEP). Las muestras consistieron en cervix uterinos producto de conizaciones y LEEPs fijados en formalina buferizada al $10 \%$ e incluidas en parafina, con periodos de almacenamiento no mayores a 2 años. Además, 10 bloques del Hospital Nacional de Niños (HNN), fijados en formalina al $15 \%$, que correspondieron a linfoma Hodgkin: 3, tumor congénito pulmón: 1 , teratoma: 1 , tumor de base hígado: 1, ependimoma: 2, osteosarcoma: 1 y tiroides:1. En todos los casos el ADN se extrajo por duplicado según el protocolo seleccionado como más efectivo.

Se realizó la PCR, para el gen de la $\beta$ globina (producto de $267 \mathrm{pb}$ ), bajo las condiciones de amplificación descritas y se determinó el porcentaje de amplificación, al evaluar los productos de amplificación en un gel de agarosa al $2 \%$.

\begin{tabular}{|c|c|c|c|c|}
\hline Método & Muestras & $\begin{array}{c}\mathbf{A D N} \\
\mathbf{\mu g} / \boldsymbol{\mu l}[\mathbf{\times}]\end{array}$ & $\begin{array}{c}\mathbf{D O}_{\text {ADN/ prot }} \\
{[\times \mathbf{\times}]}\end{array}$ & $\begin{array}{c}\text { \% } \\
\text { Amplificación }\end{array}$ \\
\hline $\mathbf{1}$ & 10 & 0,915 & 1,174 & 10 \\
\hline $\mathbf{2}$ & 10 & 0,236 & 1,505 & 50 \\
\hline $\mathbf{3}$ & 10 & 0,279 & 0,750 & 30 \\
\hline $\mathbf{4}$ & 10 & 0,072 & 1,338 & 00 \\
\hline $\mathbf{5}$ & 10 & 0,164 & 1,709 & 00 \\
\hline \multicolumn{4}{|r}{} & $\mathbf{X = 1 8}$ \\
\hline
\end{tabular}

Cuadro \# 1. Valores promedio de la concentración de $A D N$, relación $D_{A D N / p r o t ~} y$ porcentaje de amplificación obtenidos con cada protocolo a partir de 10 muestras del HSJD.

Revista electrónica publicada por la Escuela de Medicina de la Universidad de Costa Rica, 


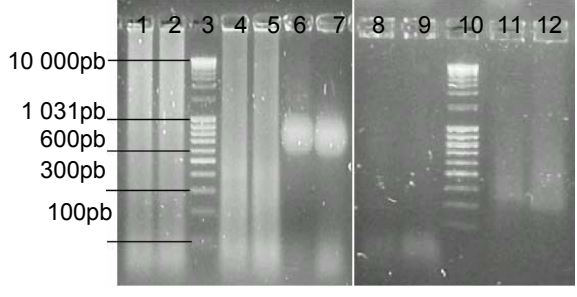

I. Evaluación de los protocolos de extracción de ADN: Cada protocolo de extracción mostró un patrón de electroforesis constante (Figura 1). Los resultados obtenidos en la cuantificación del ADN mediante espectrofotometría se resumen en el Cuadro 1; se considera que los datos de la $D_{A D N}$ son confiables cuando se encuentran entre 0,1 y 1,0 [15]. Para la relación ADN/proteínas ( $\left(\mathrm{O}_{\mathrm{ADN} / \text { prot }}\right)$, proporción de las absorbancias obtenidas a $260 \mathrm{~nm} / 280 \mathrm{~nm}$, se considera como ADN con un buen nivel de pureza cuando
Figura \# 1. Electroforesis del ADN extraído de una misma muestra del HSJD con los 5 métodos. Izquierda: carriles 1 y 2 extracción método 1, carril 3 marcador de peso molecular, carriles 4 y 5 extracción método 2, carriles 6 y 7 método 3 , carriles 8 y 9 extracción método 4 , carril 10 marcador de peso molecular, carriles 11 y 12 método 5 .

este valor se encuentra entre 1,5 y 2,0 . $[16,17]$.

Los porcentajes de amplificación resultaron variables según el método de extracción usado. El porcentaje general de amplificación para el gen de la $\beta$ globina utilizando todos los protocolos fue de tan sólo del $18 \%$.

II. Valoración del estado de las muestras de la cCSS: El promedio general de amplificación utilizando el Método 2 estuvo por debajo del 50\%. El rango de amplificación por servicio va, desde el 0\%, hasta el 70\% (Cuadro 2).

Cuadro \# 2. Porcentaje de amplificación del gen de la $\beta$-globina a partir de los ADN extraídos con el Método 2.

\begin{tabular}{|ccc|}
\hline Hospital & Muestras & $\%$ Amplificación \\
\hline HSJ D & 10 & 50 \\
\hline HNN & 10 & 60 \\
\hline HM & 10 & 60 \\
\hline HCF & 10 & 50 \\
\hline HMC & 10 & 50 \\
\hline HMP & 10 & 70 \\
\hline HTF & 10 & 40 \\
\hline HSC & 10 & 50 \\
\hline HEP & 10 & 00 \\
\hline \multicolumn{2}{c}{ Promedio } & 48 \\
\hline
\end{tabular}

Revista electrónica publicada por la Escuela de Medicina de la Universidad de Costa Rica, 2060 San José, Costa Rica. ® All rights reserved. 


\section{Discusión}

I. Evaluación de los protocolos de extracción de ADN: En los extractos de algunos métodos fue posible observar ADN de buen peso (métodos 1, 2 y 3 ), mientras que en otros se observa una degradación casi completa del material (métodos 4 y 5) (Fig. 1).

La muy baja concentración de ADN, medida por espectrofotometría, en las muestras de los Métodos 4 y 5 (inferior a $0,2 \mu \mathrm{g} / \mu \mathrm{l})$ concuerda perfectamente con lo analizado en la electroforesis. Los métodos que aplican únicamente calor para obtener el ADN, poseen resultados contradictorios según los estudios encontrados. Por ejemplo, Cao et al. y Coombs et al. aseveran haber obtenido ADN amplificable, mientras Shi et al. señalan lo contrario, como se observa en el presente estudio $[18,19,5]$. El Método 5 fue reportado por el mismo Frank et al. como el más efectivo, contradictoriamente a los resultados obtenidos en esta investigación, después de la digestión enzimática con Proteinasa K, la ebullición del ADN durante ocho minutos, es posiblemente el foco primario de degradación [9].

ADNs correspondientes a los métodos 1,2 y 3 dieron amplificaciones exitosas. Estos métodos obtuvieron los valores de concentración y pureza de ADN más altos, mismos que mostraron patrones de corrida en la electroforesis que indican ADN de alto peso. Los bajos resultados de la $\mathrm{DO}_{\mathrm{ADN} / \text { prot }}$ del Método 3, indican que la ausencia de purificación y precipitación conlleva un alto contenido de contaminantes (proteínas, solventes y detergentes) (Figura 1). El porcentaje de amplificación no fue mayor al $50 \%$ para ninguno de los métodos.

El Método 2, cuyo grado de pureza es alto, fue el protocolo de extracción más exitoso cuando de amplificación se trata.
La rehidratación paulatina de los tejidos en las fases iniciales, posiblemente omite el daño mecánico que se puede producir al manipular el ADN de las muestras fijadas en formalina. Los pasos de purificación y precipitación parecieran eliminar eficientemente los inhibidores de la PCR. Lo anterior concuerda con estudios como los de Cao et al., Libório et al., Coombs et al.y Shi et al $[18,4,19,5]$.

No fue posible encontrar anteriores experiencias con el Kit Extract-N-Amp de Sigma-Aldrich (Método 3) en muestras parafinadas. La baja calidad del ADN de la muestra pudo ser la causa del escaso porcentaje de amplificación alcanzado [13].

Los iniciadores PC04 y GH20 de la $\beta$ globina, era de esperar que mostraran una alta eficacia en la PCR por tratarse de un gen constitutivo. Bajo las condiciones señaladas se obtiene un único producto de $267 \mathrm{pb}$, el cual se corroboró mediante genotipificación ( $A B I$ Prism 310).

Uno de los resultados más preocupantes fue la debilidad de algunas de las señales de los productos de la $\beta$-globina, que pueden llevar a la interpretación de falsos negativos $y$ complicar el diagnóstico, cuando la PCR es evaluada por electroforesis en gel de agarosa. En cuyo caso, la disponibilidad de un secuenciador de ADN se hace indispensable, pero encarece significativamente los costos por muestra. La implementación y dependencia de este tipo de equipo se debe evaluar cuidadosamente.

La amplificación de material de muestras parafinadas puede verse afectada por múltiples factores, uno de ellos puede ser el tiempo de fijación, que puede originar bajas importantes en

Revista electrónica publicada por la Escuela de Medicina de la Universidad de Costa Rica, 
la eficiencia de amplificación después de una semana e inclusive 24 horas [3$5,18,20]$.

Aunque se asume que el proceso de fijación requiere aproximadamente una hora por milímetro de tejido, rutinariamente los tejidos se fijan de 24 a 48 horas, práctica que afecta directamente la calidad molecular $[9,19]$. Otros ejemplos de condiciones limitantes son el tiempo de almacenamiento, (el tiempo óptimo de análisis varía entre 1 mes, 5 años, 18 años y hasta 36 años, según los autores) el $\mathrm{pH}$ inicial del fijador utilizado y la insuficiente neutralización de la formalina $[1,3,4,9,21,22]$.

Otro tipo de fijadores, como el metanol, etanol, histochoice, el método AMeX, e inclusive variaciones en el uso de la formalina (a $4^{\circ} \mathrm{C}$ o adicionada con EDTA) han dado mejores resultados para realizar análisis moleculares [11] .

Pareciera que la recuperación de ADN viable para la PCR depende particularmente de las condiciones propias en la que se ha procesado (fijado y parafinado) y almacenado el tejido.

Las razones por las que la PCR a partir de ADN aislado de parafinadas resulta inconsistente, se pueden resumir, a grosso modo, en baja cantidad o ausencia de ADN blanco detectable, presencia de inhibidores, degradación del ADN total blanco y fragmentación de los ácidos nucleicos debido a la fijación en formalina $[4,20]$.

II. Valoración del estado de las muestras de la CCSS: Los diferentes porcentajes de amplificación obtenidos indican que el Método 2, aunque laborioso, resulta eficiente para la extracción de ADN a partir de muestras parafinadas. La extracción de fragmentos de ADN amplificables de hasta $267 \mathrm{pb}$ fue eficaz, siempre y cuando el proceso de preservación de los tejidos se haya realizado adecuadamente. Como muestran los porcentajes de amplificación altos (mayores que 50\%) de los servicios HMP, HNN y HM. Sería de gran interés evaluar las condiciones y vías de estos servicios y compararlas con el resto de servicios valorados, para eliminar puntos críticos durante el proceso que provocan la degradación del ADN.

No fue posible determinar si existe una correlación entre la concentración de la formalina: al 15\% (HNN) versus al 10\% (resto de los servicios), ni el efecto negativo del tiempo de almacenamiento; sin embargo, fue posible extraer ADN amplificable de hasta dos años (HTF).

Las diferencias claras entre la calidad del ADN de los diferentes servicios de anatomía patológica evidencian que las prácticas hospitalarias afectan de manera directa la calidad de la muestra. Estas prácticas, que incluyen: tiempo transcurrido entre la extracción de la muestra y la fijación, tamaño del tejido, periodo de uso del mismo fijador, la calidad del mismo y la duración de la fijación, estado del las embebedoras, entre otras, estuvieron fuera del control de esta investigación.

Idealmente, los tejidos deberían ser fijados inmediata y completamente cuando son extraídos, esto eliminaría o reduciría al máximo el tiempo de prefijación, para lo que resulta indispensable la colaboración directa de todo el equipo médico involucrado.

Para poder corregir en un futuro estas prácticas, se debe tener en cuenta que el proceso de preservación de los tejidos parafinados involucra a diferentes áreas hospitalarias (Cirugía, Ginecología, Medicina Interna, Gastroenterología, Dermatología y el

Revista electrónica publicada por la Escuela de Medicina de la Universidad de Costa Rica, 
Servicio de Anatomía Patológica). A su vez, esto conlleva la manipulación de la muestra por diferentes personas de

\section{Conclusión:}

El protocolo basado en la extracción fenólica, Método 2, probó ser el más eficiente para extraer ADN para ser utilizado en la PCR, a partir de material parafinado de la CCSS; sin embargo, desventajas importantes como tiempo de procesamiento, toxicidad de reactivos y costo deben ser considerados.

El fijador y el proceso de conservación de los tejidos utilizados por la CCSS puede ser efectivo para la preservación de los ácidos nucleicos. Sin embargo, el daño causado al ADN es posiblemente determinado por las condiciones propias de fijación-parafinación-almacenamiento de los servicios de Anatomía Patológica y otros relacionados con la extracción de tejido (cirugía, ginecología, medicina interna, gastroenterología y dermatología).

Cuando se utiliza formalina buferizada al $10 \%$, como agente conservador de tejidos y ácidos nucleicos se recomienda: eliminar el tiempo de

\section{Agradecimientos:}

Esta investigación se llevó a cabo gracias al financiamiento de la Vicerrectoría de Investigación de la Universidad de Costa Rica (Proyecto $\mathrm{N}^{\circ}$ 807-A6-323) y del Servicio de Patología distinta preparación académica: médicos, enfermeros, técnicos $y$ personal no especializado.

prefijación, reducir la fijación a un rango de 3 a 6 horas y fijar únicamente porciones de tejidos de 0,5 a $1 \mathrm{~cm}$.

La necesidad de determinar un diagnóstico clínico concluyente por medio de la patología molecular va aumentando con el tiempo, por lo que es importante para clínicos e investigadores hacer conciencia de los factores que afectan negativamente la calidad molecular de los especímenes y de las medidas necesarias para superarlos.

Se recomienda además ensayar la capacidad de amplificación de fragmentos de un mayor tamaño $(>270 \mathrm{pb})$, optimizar el protocolo de extracción basado en el Método 2, aumentar el número de muestras por hospital, homogenizar el área de tejido por muestra, tomar en cuenta tejidos parafinados de diferente naturaleza y determinar el efecto negativo del tiempo en la conservación. del Hospital San Juan de Dios. Gracias también a todas las personas involucradas, de los Servicios de Patología de los nueve hospitales involucrados en la investigación.

Revista electrónica publicada por la Escuela de Medicina de la Universidad de Costa Rica, 


\section{Bibliografía}

1. Bernstein, J.; Thompson, W.; Casey, G.; Dicioccio, R.; Whittemore, A.; Diep, A.; Thakore, S.; Vaziri, S.; Xue, S. \& Haile, R. Comparison of Techniques for the Successful Detection of BRCA1 Mutations in Fixed Paraffin-Embedded Tissue. Cancer Epidemiology, Biomarkers \& Prevention. 2002. Septiembre. 11: 809-814.

2. Mies, C. Molecular Biological Analysis of Paraffin-Embedded Tissues. Human Pathology. 1996. 25(6): 6 .

3. Jiménez, G. Diagnóstico Molecular de los Linfomas No Hodgkin. 2005. Reporte Proyecto No.807-A4-321. Unidad de Genética y Biología Molecular. Centro de Investigación en Hematología y Trastornos Afines. Universidad de Costa Rica, Vicerrectoría de Investigación.

4. Libório, T.; Etges, A.; Da Costa Neves, A.; Alves Mesquita, R. \& Daumas Nunes, F. Avaliação do DNA genômico obtido de biópsias de boca embebidas em parafina e arquivadas por até 40 anos. Jornal Brasileiro de Patologia e Medicina Laboratorial. 2005. Diciembre. 41(6): 405-410.

5. Shi, S.; Cote, R.; Wu, L.; Liu, C.; Datar, R.; Shi, R.; Liu, D.; Lim, H. \& Taylor, C. DNA Extraction from Archival Formalin-fixed, Paraffinembedded Tissue Sections Based on the Antigen Retrieval Principle: Heating Under the Influence of $\mathrm{pH}$. The Journal of Histochemistry \& Cytochemistry. 2002. 50(8): 1005-1011.

6. Chan, P.; Chan, D.; To, K.; Yu, M.; Cheung, J. \& Cheng, A. Evaluation of extraction methods from paraffin wax embedded tissues for PCR amplification of Human and viral DNA. Journal of Clinical Pathology. 2001 54(5): 401-403.

7. Sato, Y.; Sugre, R.; Tsuchiya, B.; Kameya, T.; Natori, M. \& Mukai, K. Comparison of the DNA Extraction Methods for Polymerase Chain 1. Reaction Amplification from Formalin-Fixed and Paraffin-Embedded Tissues. Diagn Mole Pathol. 2001. 10(4): 265-271.

8. Forsthoefel, K.; Papp, A.; Snyder, P. \& Prior, T. Optimization of DNA Extraction from FormalinFixed Tissue and Its Clinical Application in
Duchenne Muscular Dystrophy. Anatomic Pathology. 1991. 98 (1): 98-104.

9. Frank, T.; Svoboda, S. \& Shi, E. Comparison of Methods for Extracting DNA from FormalinFixed Paraffin Sections for Nonisotopic PCR. Diagnostic Molecular Pathology. Septiembre. 1996. 5(3): 220-224.

10. Miller, S.; Diker, D. \& Polesky, H. A Simple Salting out procedure for extracting DNA from human nucleated cells. Nucleic Acid Research. 1988. 6(3): 1215.

11. Morén, $P$. Linfomas ganglionares y cutáneos presentan la misma Traslocación. [online] Diario médico, Dermatología. Barcelona, España. 14 setiembre 1999. [citado 18 Mayo 2005]. Disponible en: http://www.diariomedico.com/dermatologia/n140 999.html

12. Chelex protocols (1990). In Amplitype User Guide. Cetus Corp., Emeryville, C. A.

13. SIGMA-ALDRICH. 2005. Extract DNA for Genotyping in 15 minutes. Extract-N-Amp Tissue \& Extract-N-Amp Blood. Manual.

14. Anónimo. 2007. Archivo de Protocolos del Centro Nacional de Investigaciones Oncológicas. Madrid, España.

15. QIAGEN. 2003. Reliability of DNA Quantification by Spectrophotometry. [online] [citado 1 mayo 2006] Disponible en:

http://www1.qiagen.com/Plasmid/Spectrophotom etry.aspx?

16. BMG Labtechapplication. 2002. DNA Quantification (Absorbance Mode). [online] [citado 1 mayo 2006]. Disponible en: http://www.bmglabtech.com/db assets/applicatio ns/downloads/applications/AN\%20Absorbance\% 206002.pdf

17. University Of Toledo. 2004. DNA quantification (spectrophotometry). [online]. Laboratory for Microbial Ecology of Earth, Ecological and Environmental Sciences. p. 3. [citado 1 mayo 2006]. Disponible en: 
http://www.eeescience.utoledo.edu/Faculty/Sigle r/RESEARCH/Protocols/DNA\%20quantification/ DNA\%20quantification.pdf

18. Cao, W.; Hashibe, M.; Rao, J.; Morgenstern, H. \& Zhang, Z. Comparison of methods for DNA extraction from paraffin-embedded tissues and buccal cells. Cancer Detection and Prevention. 2003. 27: 397-404

19. Coombs, N.; Gough, A. \& Primrose, J. Optimization of DNA and RNA extraction form archival formalin-fixed tissue. Nucleic Acids Research. 1999. 27(16):12-14

20. Noguchi, M.; Shuichiroh, F.; Takeuchi, T. \& Hirohashi, S. 1997. Modified formalin and methanol fixation methods for molecular biological and morphological analyses. Pathology International. 1997. 47: 685-691.

21. Srinivasan, M.; Sedmak, D. \& Jewell, S. Effect of Fixatives and Tissue Processing on the Content and Integrity of Nucleic Acids. American Journal of Pathology. 2002. Diciembre. 161(6): 1961-1971.

22. Wong, C.; Dicioccio, R.; Allen, H.; Werness, B. \& Piver, M. Mutations in BRCA1 from fixed, paraffin-embedded tissue can be artifacts of preservation. Cancer Genetic Cytogenetic. 1998. Noviembre. 107(1): 21-27.

433(Suppl) 1768.

\section{Correspondencia:}

\section{Gerardo J iménez Arce}

Centro de Investigación en Hematología y Trastornos Afines (CIHATA-UCR),

gjimenez@cariari.ucr.ac.cr

Revista electrónica publicada por la Escuela de Medicina de la Universidad de Costa Rica, 